\title{
Anthropocene: To be or not to be?
}

\author{
José Gomes dos Santos a,b,c,d, * \\ a Department of Geography and Tourism, Faculty of Arts and Humanities, University of Coimbra, Portugal \\ ${ }^{\mathrm{b}}$ CEGOT - Portuguese Inter University Centre of Geographical Studies and Land Planning \\ ${ }^{\mathrm{C}}$ GEOCART - Laboratory of Cartography, Geography Department, Federal University of Rio de Janeiro (UFRJ), Brazil \\ d SIGA - Centre of Applied Cartography, University of Brasilia (UnB), Brazil \\ * Corresponding Author. \\ E-mail address: jgs@ci.uc.pt (J. Gomes)
}

\begin{abstract}
The growing interest related to the proposal of formal definition of a new geological period that has being called "Anthropocene" has introduced a buzzing dynamics in the scientific community, but its conduct is perhaps due to various interests involved in a discussion that has long surpassed the contours of the so-called "Geosciences". Themes such as "Climate Change or Drift", "Global Warming", "Massive Extinction of Species" and "Loss of bio and geodiversity", among others, are the wheel of a geomorphogenetic dynamics of anthropocentric origin, which leads the debate. But are the conditions for the formal establishment of a new morphosedimentary cycle following the Meghalayanian (Upper Holocene) Age? This work pursues a line of thought that seeks to answer these and other questions, based on the official position of the institutes that have the scientific competence for the formalization under consideration, and the formal criteria that should be considered for this purpose.
\end{abstract}

Keywords: Anthropocene; Chronostratigraphy; Stratotype; Anthropocene Working Group; International Stratigraphy Commission; International Union of Geological Sciences 


\section{Background}

Anthropozoic, Anthropocenic, Homenogenocene, Anthrocene or even Anthropocene, are some of the most frequent terms used in the literature to which is linked the idea of entering a "new geological epoch" marked by anthropic activity and supported by human-induced stratigraphic indicators-markers.

Not already a new issue, as it was introduced for the first time in the academic and scientific discussion of the subject in 1873 by the Italian geologist Antonio Stoppani, referring to a new telluric force that in power and universal nature would be comparable to those of the largest modeler agents of the Earth (Crutzen, 2002) the expressions "Antropoceno"

(American Portuguese-speaking language) or "Antropocénico" in (European Portuguese), are the most recent designations to speak of a phenomenon that many authors defend as part of a new morphosedimentary, morpho dynamic and morphoclimatic context of the Earth. This concept may even mark the beginning of a new cycle of crustal and environmental changes with an indelible impact on terrestrial geosystemic dynamics and with chronostratigraphic significance that will follow the most recent period of the Holocene after the last phase of the Würmian glaciation.

Not being complex, this topic became very controversial, due to the high degree of intrinsic subjectivity, but, mainly, due to the fact that it reached a diffuse dimension, which surpassed the limits of science and entered the public opinion with a strong media impact carried by the "Green Tsunami" of which the last episode was starring "Greta Thunberg". It only carries a banner of fundamentalist opinions, the last but also the strongest sign of a new global and massive green trend that may affect government policies, the global economy and social dynamics, and people's behaviors and beliefs. Already entering mainstream media and digital social networks, entropy increases exponentially, accuracy is lost, and uncontrolled information often becomes misinformation and toxic waste. However, it seems to be rather strange that "While Geography has always been deeply connected with the coupled humanenvironment paradigm, physical geographer's embrace of the Anthropocene still appears lukewarm at best" (Ellis, 2017). We should take advantage of the diverse themes, topics and viewpoints of our subject by actively following a more critical approach to our research practices in order to find those geographic ties that join us and our discipline and that enable us to contribute more substantially to the Anthropocene debate (Knitter et al., 2019). But we must stress that, despite calls to reform stratigraphic practice, the disciplinarity of the AWG prevails over innovative research practices inspired by interdisciplinary exchanges (Lundershausen, 2018).

We therefore believe that addressing a short but complete set of problems and presenting them in the form of concrete questions can help to clarify some questions about the formal definition of the Anthropocene. So, let's discuss it by steps! "Anthropocene"; what is this after all? How is a new terrestrial chronostratigraphic cycle defined? Who has the skills to do so? When could it have started and what kind of scientific evidences support this thesis? Among others, these are some of the equations that need to be clearly debated because the subject feeds diverse opinions, from experts to nonexperts, and involves political and economic interests worldwide.

\section{Anthropocene: what is this and what does it mean?}

In order to avoid or try to circumvent any inaccuracies that could feed the controversy around this subject, we assume, from the outset, that only the free exercise of reflection for purely scientific purposes moves us. For this reason, we tried to understand the main currents of opinion, public and published, to stick to what is truly scientific the subject legitimates, with the common concern about the future and the debate on the sustainability of the planet.

Since its inception, the dynamics of Planet Earth, whose age, based on rigorous radiometric dating studies carried out on terrestrial rocks but also on meteorites, is estimated at approximately 4.5 billion years, has revealed a "natural alterability", both in terms of the constant interaction between climate-ocean-atmosphere, and in terms of internal geodynamics with tectonic plates and derived phenomena such as continental migration and geomorphological dynamics that shape the architecture of the planet but also its epidermis. That is, two megaphenomena on all time scales of analysis, from short time to long time, which alone would be enough to become aware of these two facts: 
- The Earth is not alone in the Celestial Space and therefore evolves since its formation in "intrinsic" terms, but also interacts with other entities (evolution due to "extrinsic" factors); this results in a complex, unpredictable but certainly dynamic evolution, which has similar profile cycles in some of its characteristics, in space and time, but it is also an interactive evolution that results from the combination of factors related to internal and external geodynamic actions, but also from its interaction with cosmic factors (geodynamics with exogenous genesis); here we can see the high uncertainty about possible factors and variables that may interfere with its evolution and the consequent constant changes that this evolution produces in planetary morpho dynamics. On the other hand, some of the cosmic factors (such as Milankovitch's orbital parameters) are known to contribute directly and indirectly to the regulation of all manifestations of the planet's evolution, including interglacial heating cycles and glaciations, variability in the duration of days and nights latitude and throughout the year, among others.

- There is an unmistakable relationship of natural multifactorial interdependence that, until the appearance of man, in rigor until the 20th century, when human activity truly begins to signal the occurrence of evident impacts on the natural dynamics of the Planet, justify the variability associated with any systemic organism, an expression that should be read in the philosophical cradle of the purity of James Lovelock's postulates. Interacting with this naturally-based morpho dynamics and paving the way for the formulation of theses and theories, counter-theses and counter-theories, some (neo) catastrophists and others (neo) uniformitarians that, in practice, only confirm the classic course of the evolution of scientific thought on the history of the Earth, human activity introduces clear disruptive signs of a

${ }^{1}$ According to the latest estimates from the Intergovernmental Panel on Climate Change (IPCC, 2018), the Earth could warm from 1.5 to $2^{\circ} \mathrm{C}$, values used in scenario simulation during this century (https://www. eea.europa.eu/themes/climate/fag/how-is- status quo that is no longer exclusively natural. We recall, however, in this regard, the studies of Georges Cuvier (French naturalist, who lived between the 18th and 19th centuries) - mentor and staunch defender of Catastrophism, a model that would inspire the creationist theories defended by some naturalists of the 19th century and the coeval studies developed by scientists sensibly contemporary with the author, such as James Hutton (1726-1797), John Playfair (1748-1819), and Charles Lyell (17971875), whose ideas revealed a clear opposition to Catastrophism. They incorporated the uniformitarian model that had as a theory the interpretation of the past based on the present. That is, downstream, it seems to us that there is nothing new (for now).

However, it is urgent to realize that some buzz expressions such as "climate changes", "climate drift", "global warming", "sea level rising ", among others, are often referred to as direct causes of anthropic activity (sometimes it seems that one wants us to believe that they are really unique). But if we pay attention at their scientific essence, we soon realize that they carry diverse and inescapable valid foundations that, at least, compel us to a deep reflection; some examples can be taken from the following:

- The decline in biodiversity is generally accepted by the scientific community and is accompanied by an unprecedented rate of species extinction;

- Over the last 150 years, the rise in terrestrial temperature - global warming ${ }^{1}$ due to increased greenhouse gas emissions, especially methane $(\mathrm{MH} 4)$ and carbon dioxide (CO2) is also a reality increasingly accepted by the scientific community;

- Fluctuations in ocean levels as well as halo chemical changes in sea waters, phenomena that can be correlated with various factors, including those described above and also with accelerated melting of the polar and continental ice caps and changes imposed on the natural regimes of the rivers due, among other reasons, to climate-changing-and-how-has-it-changed-in-the-past; https://phys.org/news/2018-11-global-years.html; https://www.ipcc.ch/sr15/). 
the construction of dams, are other facts that can be deeply reflected;

- Demographic growth, urban growth and land use without methodical concerns about land use planning and the consequent exponential increase in the consumption of natural resources that all this makes it possible to address, are equally convincing facts that are not easy to measure or quantify, implied certainly significant changes in the natural alterability of geosystemic dynamics;

- Finally, and stressing the fact that these are just some of the most important factors that invite for a deep reflection on the subject, we refer to other aspects related to what some researchers call "Trace Elements" - sedimentary signatures left by modern societies. Since the presence of chlorine in the Mount Fremont - Wyoming glaciers, where a chlorine layer has been identified that is thought to be related to nuclear testing programs dating back to the Cold War and accentuated since the 1960s (i.e. with 6070 years of activity, and growing globally), the mercury layer associated with coalfired industrial units for the production of thermoelectric energy, dating back to the 80 s of the 20th century, the evidence of the influence of human activities on the geosystem is factual and multifaceted. Although no sedimentary signature has yet been found to identify a stratotype that would eliminate any doubts about the proposed definition of a new humaninfluenced morphosedimentary cycle, the presence of plastic microparticles is an indisputable truth. It is now possible to identify its chronostratigraphic presence in various places on the Earth's surface, such as the Arctic glacier or the Rocky Mountains in the western subcontinent. Despite this, those microparticles cannot but be considered as an exotic entity to the natural context and were recently detected by scientists from the German Alfred Wegener Institute for Polar and Marine Research and the Swiss Snow and Avalanche Research Institute, materials that prevail in snow from the Alps to the Arctic (Bergmann et al., 2019).

In response to the initial question, we are quick to say that the proposal for a new geological cycle that would follow the Holocene, to which it is proposed to attribute chronostratigraphic value, under the name "Anthropocene / Anthropocene", above all, denounces an anthropocentric conception (idea which must be read without judgments of value), which cannot fail to be associated with a second generation of the "creationist" vision - now of anthropic (not divine) origin - which is opposed to naturalistic models. Being a neologism that uses the terms "Anthropos" and "Kainos" which, in the Greek language, mean "Man" and "Absolutely and unmistakably different novelty", this term has been used to denote the latest geological Time Unit, which highlights the influence of a species whose evolutionary mark has been translated into a geomodelling force with profound impacts on the natural dynamics of the planet, on a global scale, comparable to the forces that govern the natural phenomena of the terrestrial system.

From much evidence, some of which were described above, Paul Crutzen (Nobel Prize in Chemistry in 1995) was perhaps the most active scientist by invoking and promoting the term "Anthropocene", coined in the 1980s of the 20th century by the American limnologist Eugene F. Stoermer, but whose paternity this author never formally assumed. Among the large spectrum of Crutzen's publications ${ }^{2}$, regarding only the works in which he emerges as sole author, stands out the remarkable work published in the Nature Magazine, entitled "Geology of mankind" (Crutzen, 2002). We must stress that this is a very impressive paper, one of his most cited works, with more than 4000 citations and, along with others such as "The Anthropocene" (Crutzen, 2006), also with almost 4000 citations.

\section{How is a new terrestrial chronostratigraphic cycle defined?}

How can we finally define a new geological cycle and a new morphosedimentary signature and its chronostratigraphic markers? In fact, it is not easy and is far from peaceful although there are very clear rules, but the debate on the subject has already gone beyond geosciences.

${ }^{2}$ According to Google Scholar sources 
Some authors even point out the existence of conceptual and operational weaknesses in the application of the chronostratigraphic model by AWG; for example, Ruddiman, (2018) identifies three flaws in this method, in defining an isochronous chronostratigraphic timeline to signify the onset of the proposed new Anthropocene time division. Integrating this current of thought, other authors (Edgeworth et al., 2019) regard the method as a profound barrier to developing a scientifically useful stratigraphic definition of the Anthropocene

On the other hand, Peter Brannen's ideas must be heard when he says that "...there exists a better word in geology than epoch to describe our moment in the sun thus far: event" (https://www. theatlantic.com/science/archive/20 19/08/arrogance-anthropocene/595795/).

Responding to Ruddiman's ideas concerning the 'three-flaws' in defining a formal Anthropocene, in Zalasiewicz et al., (2019) one can see an an hybrid interpretation model which consists in regarding a formal Anthropocene that can be "compatible with but distinct from its diachronous anthropogenic counterparts".

As Ferrão (2017a) we think that maybe we will be facing a window of opportunity so that, reviewing the concept, the discussion on the topic may be useful because "(...) it introduces a new reading of the present - the Anthropocene as a scientific event - and thus increase the ability to imagine desired futures - the Anthropocene as a philosophical and political event".

Although it is not the central object of this reflection exercise, as it is objective and practical, and because it takes the form of formal and scientific reflection on a topic that has come to the order of common concerns at a global level, this perspective could not fail to be invoked. However, if we focus on the scientific validation of the problem related to the above formulation, it should be noted that the proposal for a new geological cycle, that is, a new morphosedimentary signature, lacks clear facts and grounds, such as novelty and break with "something that comes from behind". In this sense, it was mandatory to identify a stratotype that contains these unambiguous elements, what some authors call a "golden spike", the piece that would make up the puzzle. But even if the stratotype that would provide the base condition for defining a new geological cycle chronostratigraphic - based has not been found, the presence of plutonium resulting from (the above mentioned) nuclear tests in sedimentary formations is a fact. And the presence of plastic particles incorporated in sedimentary formations can also contribute to legitimize the claim that these new environmental indicators are some of the formalisms necessary to ensure one of the premises for the viability of the proposals for the formal definition of a new chronostratigraphic unit, that is, the existence of "absolute and unequivocal novelty, unlike anything that existed", in this case, based on the idea that "Man" and anthropic activity function as "landscape shaping agent" capable of producing sensitive changes in the natural dynamics of the terrestrial system. So, we would be faced with a model that some authors (Ferrão, 2017b) refer to as being regulated by man (the time of man), but which is also called the "geo-constructivist" model (Bogalheiro, 2018). On the other hand, as defended by the authors of the most recent Report ${ }^{3}$ "Results of binding vote by AWG" (May 2019), in addition to what it introduces "as absolute novelty", anthropic activity should be read by the consequences of disturbances to natural systemic dynamics, such as "(...) increased order of magnitude in erosion and sediment transport associated with urbanization and agriculture; severe anthropogenic disturbances in the bio-geochemical cycles of elements such as carbon, nitrogen, phosphorus and various metals, together with new chemical compounds; environmental changes produced by these disturbances, including global warming, sealing, seawater acidification and expansion of 'dead zones'; rapid changes in the biosphere on land and sea as a result of habitat loss, predation, explosion of domestic animal populations and species invasions; proliferation and global dispersion of many new 'minerals' and 'rocks', including concrete, atmospheric ash and plastics, as well as the myriad of 'techno fossils' produced from these and other materials".

According to AWG' Report (Working Group on the "Anthropocene," 2019) many of these changes will persist for several millennia or more and are producing substantive changes in the path of the earth system, some with permanent effect. These changes are shaping a new body of sediment whose chrono (and litho)

${ }^{3}$ Conducted by the Anthropocene Working Group (AWG). 
stratigraphic signature reveals potential for preservation in the extreme future".

\section{Who has the skills to define a new terrestrial chronostratigraphic cycle?}

The term Anthropocene has been the subject of much debate in the scientific and academic fields, but also in other fora. On the other hand, several initiatives were born, such as the individualization, in 2009, of the Anthropocene Working Group (AWG) as part of the SubCommission on Quaternary Stratigraphy (SQS), a constituent body of the International Commission on Stratigraphy (ICS).

According to Ferrão (2017b) in 2015 a thematic issue of the journal Geographical Research on "Anthropocene Geographies" is published. Quoting Castree (2016), Ferrão (2017b) points out that, in 2015 and 2016 several articles on the Anthropocene were published in prestigious journals such as Nature and Science, which reflects the degree of scientific maturity achieved in this thematic domain.

It is also interesting and useful the exercise that Ferrão develops (Ferrão, 2017b), that searching Google Scholar for the term "Anthropocene", the answers obtained allowed to identify about 1,700 references, 291 publications. with the word "Anthropocene" in the title, 425 being registered in the Web of Science and 550 in Scopus (Harrington, 2016 quoted in Ferrão, 2017b).

The words of Castree (2014), also quoted in Ferrão (2017b) convey a very powerful message when he states that " $(\ldots)$ it is true that the Anthropocene remains a 'teen' concept of an uncertain future". In the same work, in a Google search exercise for the term, in English but also in Portuguese/Castilian, the author refers to a significant increase in the number of results returned by the platform, which are documented as a timeline for the 2009-2016 time window.

It occurred to us to carry out a similar research with the purpose of understanding which indicators that the evolutionary line that reflects the interest in the search of the term in English (Fig. 1) and in Portuguese/Castilian (Fig. 2) would provide us with updated data. Despite the irregularity of the layout, a general upward trend is evident in both cases, and these indicators confirm the thesis that the topic continues to arouse growing interest.

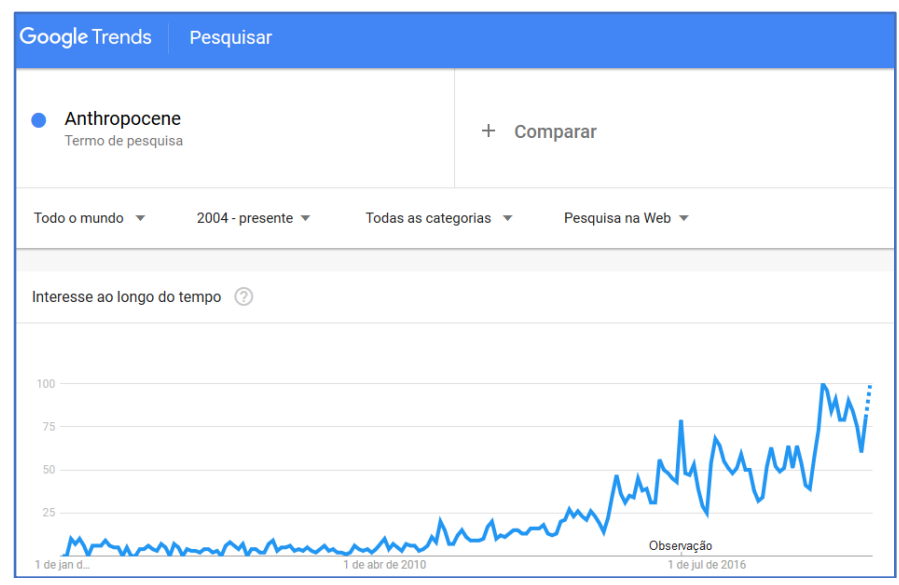

Fig. 1. Timeline evolution of the interest in the term "Anthropocene".

Source:https://trends.google.com/trends/explore?date=all $\& q=$ Anthropocene, accessed September 11, 2019).

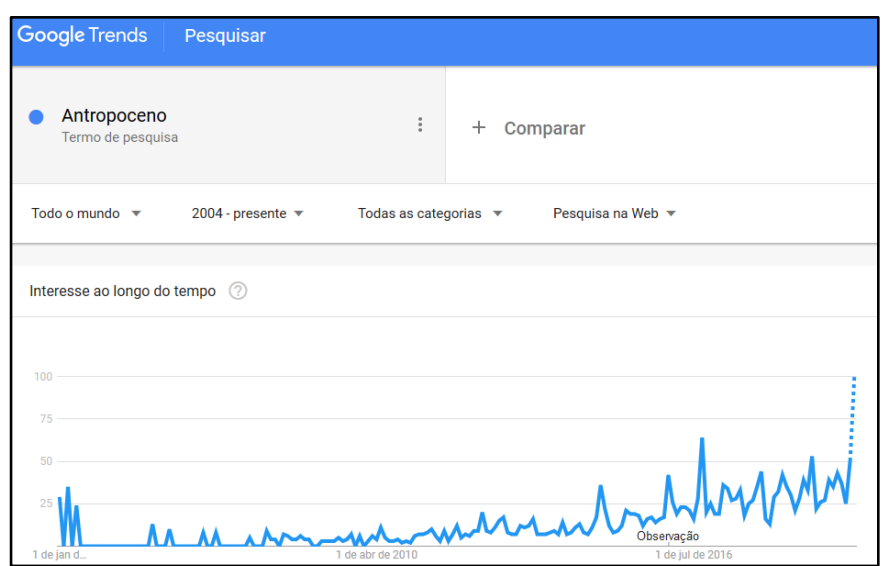

Fig. 2. Timeline evolution of the interest in the term Anthropocene.

(Source:https://trends.google.com/trends/explore?date=a $\underline{\| \& q=A n t h r o p o c e n e}$, accessed September 11, 2019).

Realizing that the interest in the theme went beyond the scope of the parent disciplines (Geosciences), we cannot leave to associate us with the idea that the formal institutes should exercise their competencies in order to define, promote and implement the formal procedures for the implementation of a new morphosedimentary cycle with a formally identified stratotype and for the individualization of new chronostratigraphic cycles. And it happened indeed. The AWG Report, published in May 2019, is very clear when it states that "(...) The Anthropocene is not currently a formally defined geological unit within the Geological Time Scale; officially we still live in 
the Meghalayan $\mathrm{Age}^{4}$ of the Holocene Epoch/Series (Fig. 3). However, a proposal is under development to formalize the Anthropocene".

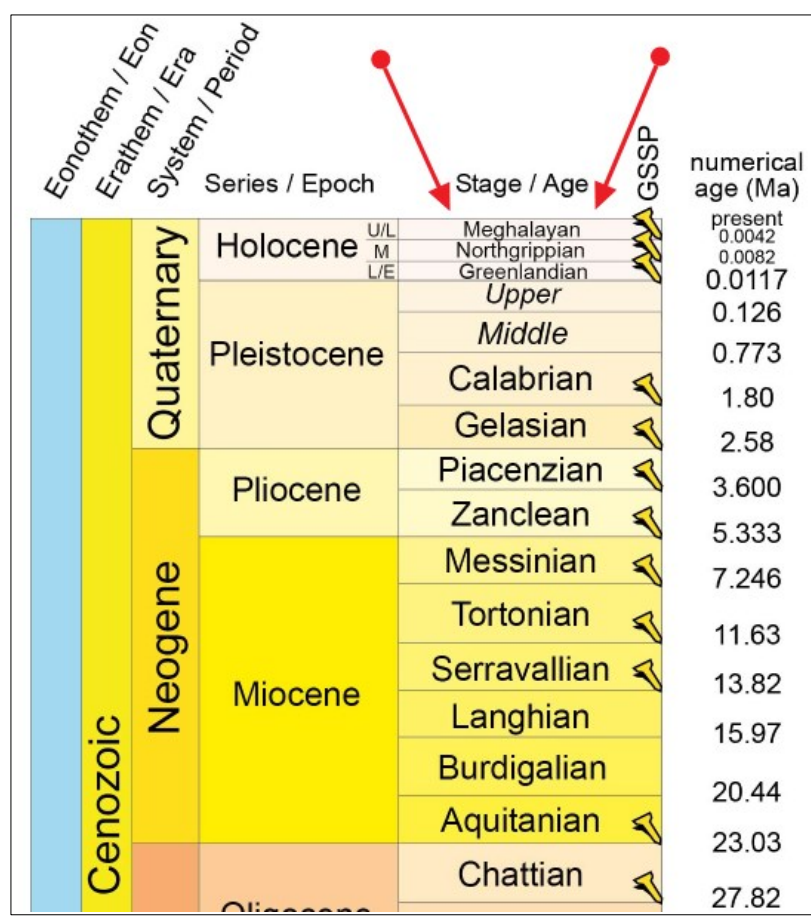

Fig. 3. Excerpt from the latest version (May 2019) of the official Geological Timetable (ICS).

(Source:http://www.stratigraphy.org//CSchart/Chronostrat Chart2019-05.jpg, accessed September 12, 2019).

According to the Report, in general terms, to be accepted as a formal geological unit of time, the Anthropocene must meet certain requirements, in particular:

- Must be scientifically justified, i.e. the 'geological sign' that is currently being produced in sedimentary formations must be significantly large, clear and distinct (absolute novelty); in fact, sufficient evidence is being gathered to demonstrate this phenomenon;

- Should be useful as a formal term for the scientific community. This requirement, concerning the reasons that have been presented and discussed throughout this work, is already clearly ensured as evidenced by the numerous scientific publications that have been evidencing

\footnotetext{
${ }^{4}$ Whose stratotype (Global Boundary Stratotype Section and Point - GSSP) is represented in a sedimentary, stalagmitic concrete formation preserved in the Mawmluh Cave located in northeastern India (International Union of Geological Sciences - IUGS, 2018, http://quaternary.stratigraphy.org/iugs-ratifies-holocenesubdivision/). This proposed new formal Holocene framework resulted from a decision of the IUGS Executive
}

the growing interest of the community in relation to the subject. However, its value as a formal geological unit of time remains to be discussed.

Based on the preliminary recommendations made by AWG in 2016, this proposal is under development according to various criteria, which indicate the strength ideas to answer the last of four question set defined at the beginning of this study which is documented as follows.

\section{When could it have started and what scientific evidence supports this thesis?}

In line with the narrative we have been developing, we have taken up the idea that the formal definition of a new geological unit of time must meet very clear and unavoidable criteria. Preliminary recommendations made by AWG in 2016 state that the acceptance and validation of the Anthropocene / Anthropocene proposal as a new chronostratigraphic unit is being developed according to the following criteria:

- Is being considered at the Series/ Epoch level (and therefore its base/beginning closes the Holocene Series/Epoch, as well as the Meghalayanian Stage/Age;

- Will be defined by the formal means and established as the standard for a unit of Geological Time, through a stratotype (GSSP), a concept that as being colloquially referred as "golden spike";

- Ideally, its beginning can be traced back to the middle of the 20th century, coinciding with a set of geological proxy data preserved in sedimentary formations that reveal a genesis quite distinct from the sedimentary profiles of the Meghalayanian series, and may be associated with the "Great Acceleration" of population growth, industrialization and globalization;

- The clearest and most synchronous signal, which shows universal presence and may be a primary marker, are the artificial plutonitic radionuclides spread throughout the world as a result of the

Board. The Meghalayan Age should have started 4250 years ago Before Present (BP), that is, before 1950, which serves as a chronological marker for coinciding with nuclear weapons testing, and paves the way for the definition and formal acceptance of the Anthropocene as a geological Time Unit. 
aforementioned thermonuclear weapon tests - it means that this could be called a "bomb spike" (Zalasiewicz et al., 2017) - which date from the 1950s. However, it has become clear that the geological community is more comfortable with a GSSP (Finney and Edwards, 2016). Analyzes of possible sites to propose as "golden spike" are ongoing. The resulting proposal, when formally launched, will require an absolute majority agreement (> 60\%) of AWG and its parent bodies (successively SQS and ICS), as well as ratification by the IUGS Executive Board (see Fig. 5). However, as the Report (Working Group on the "Anthropocene," 2019) states, "the success of this proposal is not guaranteed".

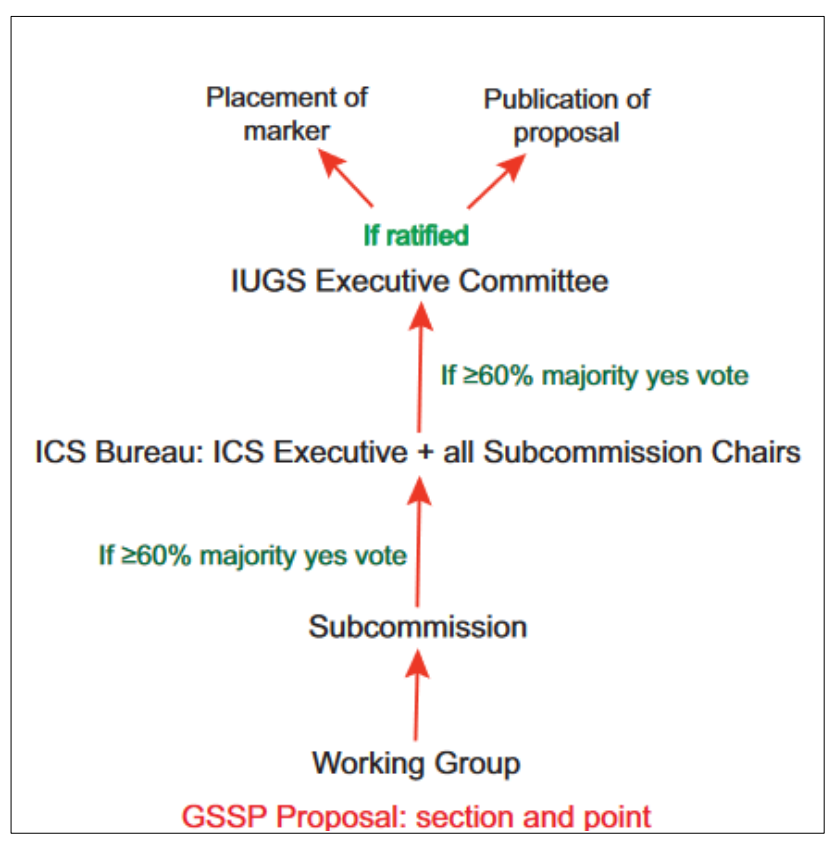

Fig. 5. Workflow for approval and rectification of a GSSP proposal (Finney and Edwards, 2016).

It is worth mentioning that, according to Zalasiewicz et al., (2015) the majority opinion in the AWG considers the Anthropocene to be stratigraphically real and recommends formalization in the classification of Epoch/Series based on a mid-20th century limit, as is being mentioned.

This document is intended only to present (and critically reflect) on the controversy surrounding the term but, above all, on the concept of the Anthropocene as a new geological Time Unit marked by anthropic activity, whose interest is heightened since the turn of the second millennium.

And one cannot fail to point out that if, for the first formal requirement, the geological sign (the identification of the GSSP) has not yet been identified, there is no doubt, however, that the second requirement (usefulness of the theme for the scientific community) is already assured.

\section{Conclusion}

Despite the high capacity for influence that some people or even entities and institutions may exert on official bodies, the concept of Anthropocene has not yet formally succeeded. According to the Report (Working Group on the "Anthropocene," 2019) specific criteria are required for a new post-proposal and properly substantiated Geological Time Unit to be accepted. We recall the two main criteria discussed in the body of this document:

- Must be scientifically justified, ie the "geological sign" that is currently being produced in sedimentary formations must be significantly large, clear and distinct (absolute novelty);

- Should be useful as a formal term for the scientific community. This requirement is already clearly ensured as evidenced by the numerous scientific publications that have been evidencing the growing interest of the community in relation to the subject. However, its value as a formal geological unit of time remains to be discussed.

The matrix of this critical reflection exclusively assumes the banner of Science, and it is focused on the possibility of definition of a new Geological Time Unit - the "Series/Epoch of Man" as a new morphosedimentary cycle that follows the Series/Holocene Epoch. This is already a theme that ensures the high interest of the scientific community but still needs to observe the first of the mentioned criteria - the "geological sign" - which testifies to the importance of Man as a modeling agent of the planet, and which can be dated from mid-20th century. However, it has not yet been unequivocal or irrefutable because the "golden spike" - GSSP - that can guarantee the fulfillment of the first of the mentioned criteria has not yet been identified. The morphosedimentary signature will therefore work as a guarantee of this chronostratigraphic transition for which we await, and which will materialize a new anthropocentric conception of the dynamics of change in changing geosystemic dynamics. 


\section{Acknowledgments}

This work was supported by the European Regional Development Funds, through the COMPETE 2020 - Operational Programme 'Competitiveness and Internationalization', under Grant POCI-01-0145- FEDER-006891; and by National Funds through the Portuguese Foundation for Science and Technology (FCT) under Grant UID/GEO/04084/2013.

\section{Co-financed by:}

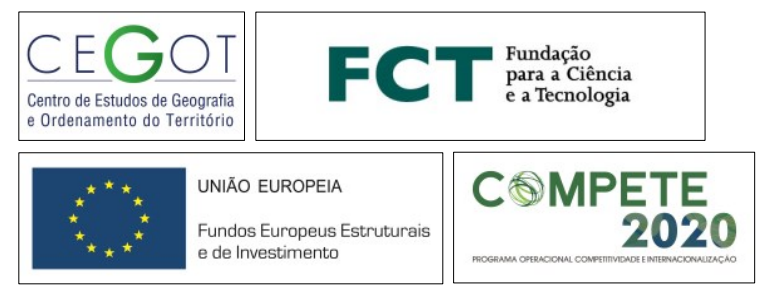

\section{References}

Bergmann, M., Mützel, S., Primpke, S., Tekman, M. B., Trachsel, J., \& Gerdts, G. (2019). White and wonderful? Microplastics prevail in snow from the Alps to the Arctic. Science Advances, 5(8). https://doi.org/10.1126/sciadv.aax1157

Bogalheiro, M. (2018). O Fim Da Natureza: Paradoxos E Incertezas Na Era Do Antropoceno E Do Geo-Construtivismo. RCL Revista de Comunicação e Linguagens | Journal of Communication and Languages, 48, 48-66.

Crutzen, P. J. (2006). The "Anthropocene." In K. T. (eds) Ehlers E. (Ed.), Earth System Science in the Anthropocene. (pp. 13-18). Springer, Berlin, Heidelberg. https://doi.org/https://doi.org/10.1007/3-54026590-2_3

Crutzen, Paul J. (2002). Geology of mankind. Nature, 415(6867), 23.

https://doi.org/10.1038/415023a

Edgeworth, M., Ellis, E. C., Gibbard, P., Neal, C., \& Ellis, M. (2019). The chronostratigraphic method is unsuitable for determining the start of the Anthropocene. Progress in Physical Geography, 43(3), 334-344. https://doi.org/10.1177/0309133319831673

Ellis, E. C. (2017b). Physical geography in the Anthropocene. Progress in Physical Geography, 41(5), 525-532. https://doi.org/10.1177/0309133317736424

Ferrão, J. (2017b). Antropoceno, Cidades e Geografia. In Espaços e Tempos em Geografia - Livro Homenagem a António Gama (pp. 287302). Imprensa da Universidade de Coimbra. https://doi.org/https://doi.org/10.14195/978-
989-26-1343-7_15

Ferrão, João. (2017āa). O Antropoceno como narrativa: uma lente útil para entender. Biblos: Revista Da Faculdade de Letras Da Universidade de Coimbra, 3, 205-221.

Finney, S. C., and Edwards, L. E. (2016). The "Anthropocene" epoch: Scientific decision or political statement? In GSA Today (Vol. 26, Issue 3). https://doi.org/10.1130/GSATG270A.1

Knitter, D., Augustin, K., Biniyaz, E., Hamer, W., Kuhwald, M., Schwanebeck, M., \& Duttmann, R. (2019). Geography and the Anthropocene: Critical approaches needed. Progress in Physical Geography, 43(3), 451-461. https://doi.org/10.1177/0309133319829395 Lundershausen, J. (2018). The Anthropocene Working Group and its (inter-)disciplinarity. Sustainability: Science, Practice, and Policy, 14(1), 31-45. https://doi.org/10.1080/15487733.2018.154168 2

Ruddiman, W. . (2018). Three flaws in defining a formal 'Anthropocene.' Progress in Physical Geography: Earth and Environment, 42, 451461.

https://doi.org/10.1177/0309133318783142

Working Group on the "Anthropocene." (2019). Subcommission on Quaternary Stratigraphy Working Group on the 'Anthropocene 'Results of binding vote by AWG Released 21st May 2019.

http://quaternary.stratigraphy.org/workinggroups/anthropocene/

Zalasiewicz, J., Waters, C. N., Head, M. J., Poirier, C., Summerhayes, C. P., Leinfelder, R., Grinevald, J., Steffen, W., Syvitski, J., Haff, P., McNeill, J. R., Wagreich, M., Fairchild, I. J., Richter, D. D., Vidas, D., Williams, M., Barnosky, A. D., \& Cearreta, A. (2019). A formal Anthropocene is compatible with but distinct from its diachronous anthropogenic counterparts: a response to W.F. Ruddiman's 'three flaws in defining a formal Anthropocene. Progress in Physical Geography, 43(3), 319333.

https://doi.org/10.1177/0309133319832607

Zalasiewicz, J., Waters, C. N., Summerhayes, C. P., Wolfe, A. P., Barnosky, A. D., Cearreta, A., Crutzen, P., Ellis, E., Fairchild, I. J., Gałuszka, A., Haff, P., Hajdas, I., Head, M. J., Ivar do Sul, J. A., Jeandel, C., Leinfelder, R., McNeill, J. R., Neal, C., Odada, E., ... Williams, M. (2017). The Working Group on the Anthropocene: Summary of evidence and interim recommendations. Anthropocene, 19(August), 55-60.

https://doi.org/10.1016/j.ancene.2017.09.001

Zalasiewicz, J., Waters, C. N., Williams, M.,

Barnosky, A. D., Cearreta, A., Crutzen, P., Ellis, E., Ellis, M. A., Fairchild, I. J., Grinevald, J., 
Haff, P. K., Hajdas, I., Leinfelder, R., McNeill, J., Odada, E. O., Poirier, C., Richter, D.,

Steffen, W., Summerhayes, C., ... Oreskes, N. (2015). When did the Anthropocene begin? A mid-twentieth century boundary level is stratigraphically optimal. Quaternary International, 383, 196-203.

https://doi.org/10.1016/j.quaint.2014.11.045

\section{Uniform Resource Locators (URLs)}

https://phys.org/news/2018-11-global-years.html, (accessed on August 30, 2019).

https://www.eea.europa.eu/themes/climate/faq/howis-climate-changing-and-how-has-it-changed-inthe-past, (accessed on September 2, 2019 ). https://www.ipcc.ch/sr15/(accessed on

September 2, 2019).

https://scholar.google.pt/scholar?hl=pt-

PT\&as_sdt $=0 \% 2$ C5\&as_vis $=1 \& q=P a u l+c r u t z e n$

$+\& b \operatorname{bth}=$, (accessed on September 11, 2019).

https://trends.google.com/trends/explore?date=all\& $\mathrm{q}=$ Antropoceno, (accessed on September 11, 2019).

http://www.stratigraphy.org/lCSchart/Chronostra tChart2019-05.jpg (accessed on November 24, 2019).

http://quaternary.stratigraphy.org/iugs-ratifiesholocene-subdivision/, (accessed on November 24, 201).

https://www.theatlantic.com/science/archive/20 19/08/arrogance-anthropocene/595795/, (accessed on February 12, 2020). 
